\title{
Histopathological findings in two cases of torsade de pointes with conduction disturbances
}

\author{
Lino Rossi and Luigi Matturri \\ From the 2nd Institute of Pathology of the University of Milan, Italy
}

Histological studies were made of the conducting system and the myocardium in two cases of torsade de pointes with complex disturbances of impulse conduction and formation. A fairly similar clinicopathological pattern was seen, consisting of an unusual association of non-interruptive, widespread damage to the conducting system with the intermittent and variable electrocardiographic disorders. The inherent desynchronization of cardiac action and the bilateral, uneven, and partial disruptions of the bundle-branches have been tentatively correlated, pathophysiologically, with the re-entry circuit, or mechanism, which is held to be responsible for the cyclic fluctuation of $Q R S$ axis, peculiar to torsade de pointes.

Torsade de pointes, a form of life-threatening ventricular tachyarrhythmia in which the QRS polarity oscillates over runs of 3 to 20 beats, was recognized long ago (MacWilliam, 1923) and has been defined more recently by Dessertènne (1966, 1967). Yet, neither the peculiar nature of torsade de pointes nor its denomination is unanimously accepted.

Recently an authoritative editorial by Krikler and Curry (1976) carefully considered the semantic etymology, pathophysiological aspects, and clinical features of torsade de pointes; the conclusion was reached that it should be treated diagnostically as a separate arrhythmia, being an 'atypical ventricular tachycardia'. It is peculiar to this arrhythmia to be frequently associated with major disturbances in impulse formation and conduction, with bradycardia (Han et al., 1966; Motte et al., 1970).

The aetiological bases (see Krikler and Curry, 1976) encompass congenital defects (prolonged QT syndrome), acquired heart diseases (myocarditis, coronary atherosclerosis), myocardial infarction (rarely), Prinzmetal's variant angina, electrolytic disorders (hypokalaemia, hypomagnesaemia), and pharmacological overdose or side effects (diuretics, quinidine, lignocaine, amitryptiline and some other antidepressant drugs). From the pathophysiological standpoint the arrhythmia seems to be the result of unsynchronized cardiac activation (Han et al., 1966) and/or impaired repolarization, favouring a particular re-entry pattern (Raynaud et al., 1969; Evans et al., 1976).

Received 28 June 1976.
The morphological basis of torsade de pointes is largely unknown: only a brief macroscopical annotation of moderate coronary atherosclerosis exists in one case (Benaim et al., 1975), histological documentation of myocarditis in another (Somerville, 1975), and in a third case there is a vague record (Krikler and Curry, 1976).

While being aware of the limitations of clinicopathological information in relation to the mechanisms of ventricular tachyarrhythmias (Rossi, 1969), this lack of data seems to justify this histological study of the association of lesions of the conducting system with torsade de pointes in the present two cases.

\section{Subjects and methods}

Two subjects who had developed torsade de pointes in the course of severe, intermittent, and varied disturbances in impulse conduction and formation were studied. Clinico-electrocardiographic and postmortem data were reviewed and correlated with a detailed study of the histological findings in the atrioventricular conducting system, to permit a reliable anatomoclinical comparison.

At necropsy a single block (besides different fragments for routine control studies) was cut away from each heart, encompassing the lower atrial and almost the entire ventricular septum, with the central fibrous body in between. This block, containing the node of Tawara with its atrial approaches, the common bundle and most of the bundle-branches was serially sectioned (every 
A

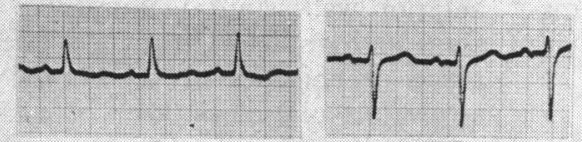

I

III

B
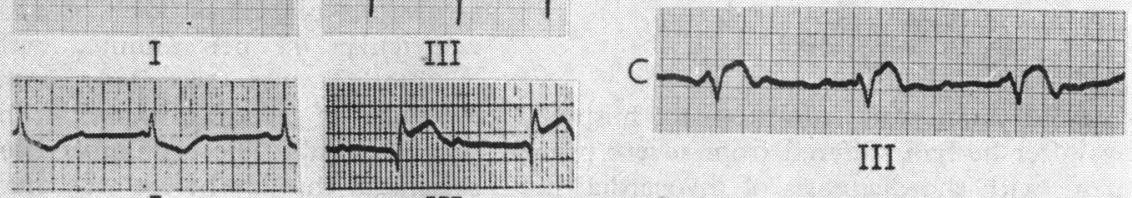

III

D

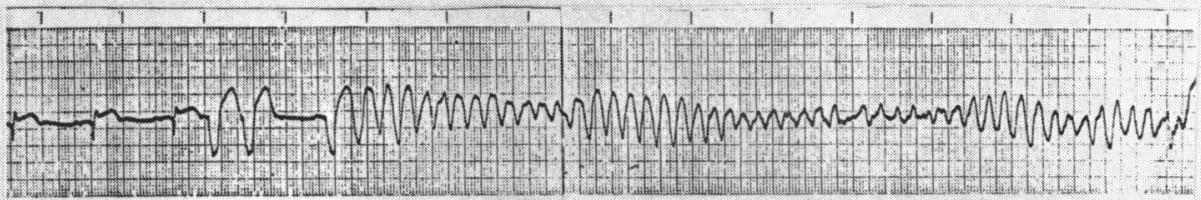

III

FIG. 1 Electrocardiograms of Case 1. (A) Pronounced left axis deviation, receded one day later (B) with the onset of atrioventricular block with narrow $Q R S$ complexes. (C) Atrioventricular and intraventricular conduction disturbances during cardiac monitoring. (D) Prolonged $P Q$ interval and a late extrasystole falling on the $U$ wave, followed by bursts of torsade de pointes.

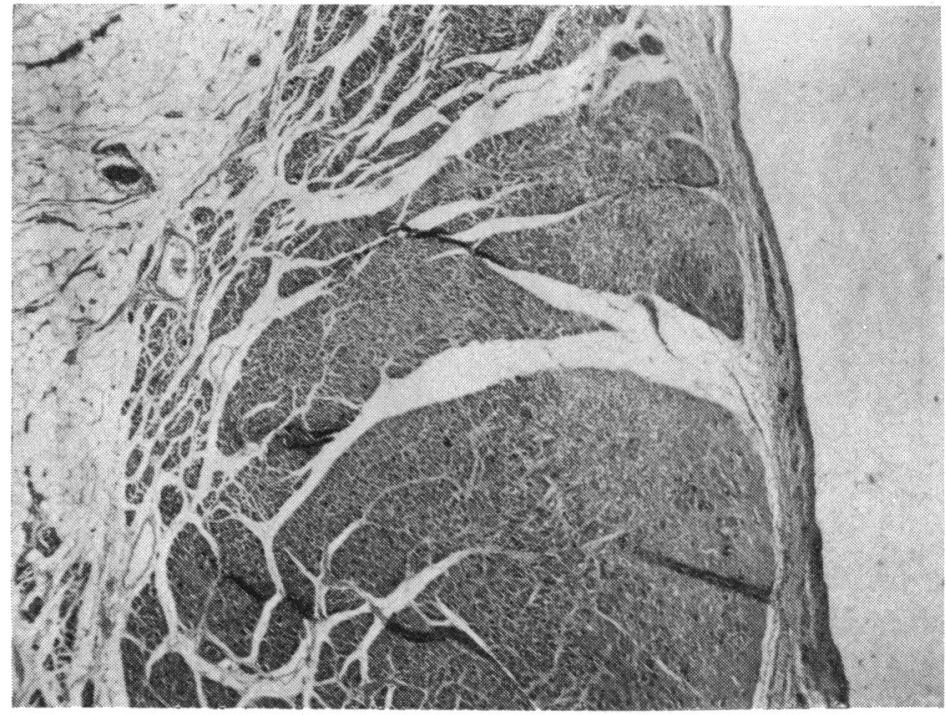

FIG. 2 Case 1. Recent myocardial infarction of the right atrium, close to the approaches to the atrioventricular node. ( $H$ and $E \times 12$.) 
$150 \mu$ ) along the longitudinal plane of the septa and perpendicularly to their endocardial surfaces (see Rossi, 1969). The slides were stained with haematoxylin-Eosin ( $\mathrm{H}$ and $\mathrm{E}$ ) and, occasionally, with trichromic Azan.

\section{Case 1}

\section{Case reports}

A 55-year-old man was admitted to hospital, three days after he had suffered from severe praecordial pain, with the diagnosis of myocardial in- farction. The first electrocardiogram showed evidence of acute myocardial infarction of the anterior wall, sinus tachycardia, and episodes of sinus arrhythmia. Three days later, during recurrence of episodes of praecordial pain, complete atrioventricular block (atrial rate 85 per minute and ventricular 48 per minute, with narrow QRS complexes) was recorded, with superimposed evidence of acute myocardial infarction of the posterior wall. The pronounced left axis deviation registered the day before was much reduced (Fig.

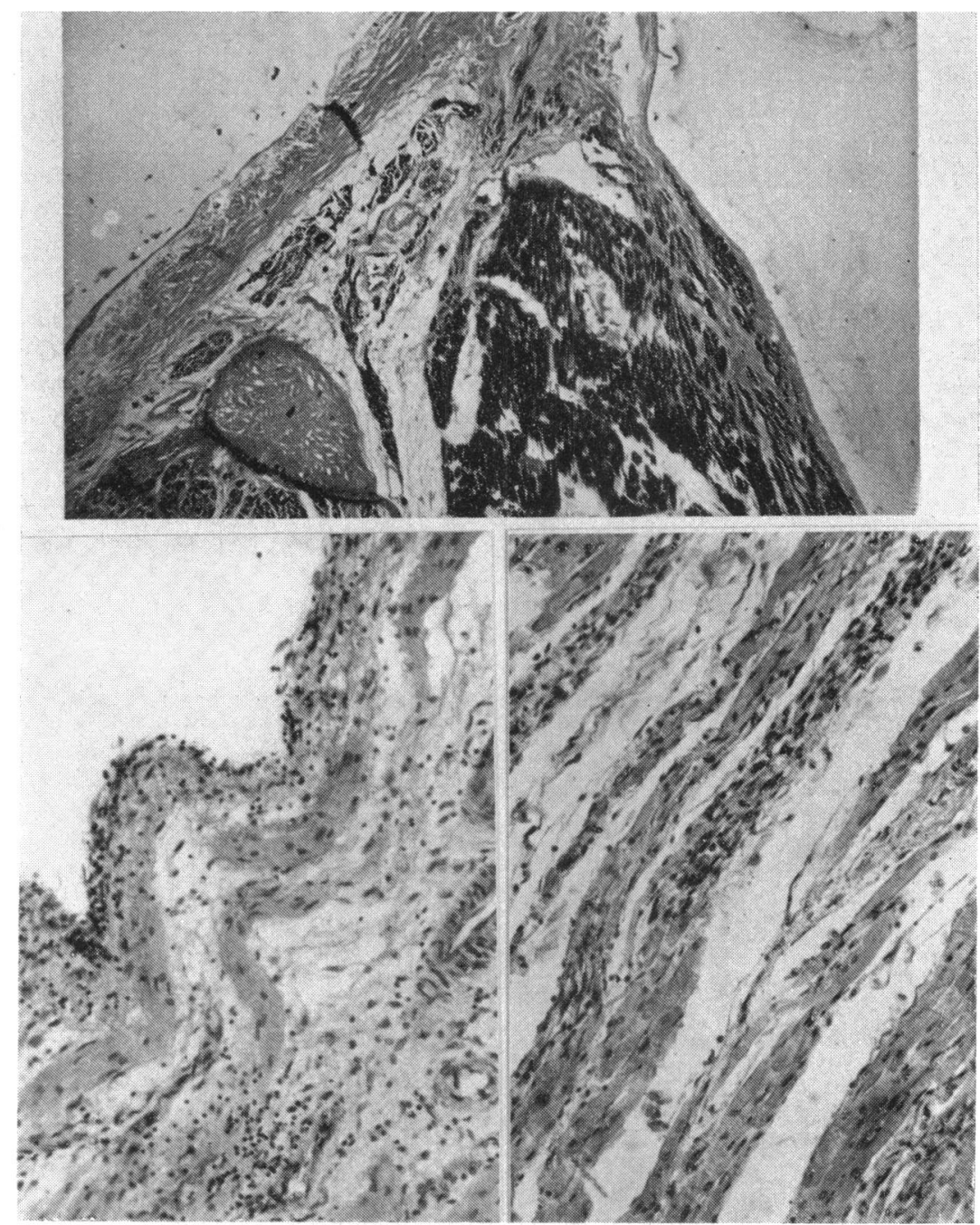

FIG. 3 Case 1. Above: The atrophic bifurcation of the His bundle, on the left side of the septal summit, contains interstitial fat cells; the intramural root of the right bundle-branch is also shown. Below left: Fibres of the left bundle-branch involved in subendocardial oedema and leucocytic infiltration from adjacent acute myocardial infarction. Below right: The right bundle-branch, in its intramyocardial course, partially damaged by recent myocardial infarction. (Above: Azan $\times 22$; Below: $H$ and $E \times 115$.) 
$1 \mathrm{~A}, \mathrm{~B})$. The following day the atrioventricular block underwent variations from complete to firstdegree, and ventricular extrasystoles with attacks of ventricular fibrillation occurred. The patient was monitored and an endocardial electrode for demand pacing was inserted; the atrioventricular block continued to vary from second to first degree (ventricular rate 50 to 60 per minute). Direct current countershock was employed twice and lignocaine (100 mg) was twice injected intravenously, to stop life-threatening paroxysms of ventricular fibrillation. Ventricular extrasystoles and bursts of torsade de pointes were also recorded (Fig. $1 \mathrm{D}$ ); periods of atrial tachycardia were also recorded. The QRS complex occasionally widened (Fig. 1 C), becoming progressively aberrant, and the ventricular rate fell to 30 per minute until death occurred as the result of irreversible ventricular fibrillation.

At necropsy, cardiac hypertrophy, severe coronary atherosclerosis, and extensive, early myocardial infarction of the left ventricular walls and of the septum were found, and histologically confirmed.

The histological study of the conducting system showed a normal sinoatrial node, patchy areas of subacute atrial infarction (Fig. 2) close to the posterior approaches to a well-preserved atrioventricular node; the lower common bundle contained interstitial fat cells and the bifurcation was also very atrophic. The bifurcation (Fig. 3) was located on the left side of the ventricular septum and gave rise to a precociously intramural right bundle-branch, with a long intramyocardial course; the left bundle-branch had a normal configuration. The ventricular septum was packed with confluent areas of fresh and recent myocardial infarction, with necrosis and severe degeneration of fibres, extensive leucocytic infiltration and patchy haemorrhage, and early macrophagic and fibroblastic activity. The left bundlebranch was partially involved in changes around the margin of the infarct (subendocardial oedema, leucocytic infiltration, and haemorrhage-Fig. 3), whereas the right bundle-branch in its intramural course was directly and more seriously affected, though not totally interrupted, by changes of recent infarction (Fig. 3).

Summing up, the alterations of the posterior approaches to the atrioventricular node, the atrophy of the common bundle and the bilateral, though incomplete, disruption of the bundle-branches may account, anatomoclinically, for the electrocardiographic evidence of variable atrioventricular block with transient impairment of bundle-branch conduction (particularly right).

\section{Case 2}

An 87-year-old man entered the hospital for cardiac failure and pulmonary tuberculosis. Electrocardiograms (monitoring periods included) showed atrial arrhythmias, incomplete $(3: 1)$ and occasionally complete (ventricular rate about 40 per minute), atrioventricular block, depressed ST segment and deep negative $T$ waves, with prolongation of $Q T$ interval ( $0.60 \mathrm{~s}$ at a rate of 40 per min); ventricular extrasystoles and short bursts of torsade de pointes (Fig. 4 A) and of ventricular tachycardia and fibrillation occurred. During phases of complete atrioventricular block the QRS complexes were widened (patterns of right bundle-branch block type-Fig. 4 B). The patient died from syncope, 22 days after admission.

At necropsy, the heart was enlarged owing to dilatation and hypertrophy; the endocardium and valves were normal; the myocardium was brownishyellow and the coronary arteries showed severe atherosclerosis. No relevant histological pictures, besides the confirmation of the foregoing changes, were seen.

The histological study of the conducting system showed fibrosis of the atrioventricular node (Fig. 5), degeneration and sclerosis of the common bundle; the bifurcation that was located on the right of the septal summit was partially affected on its left side, a large number of the fibres of the origin of the left

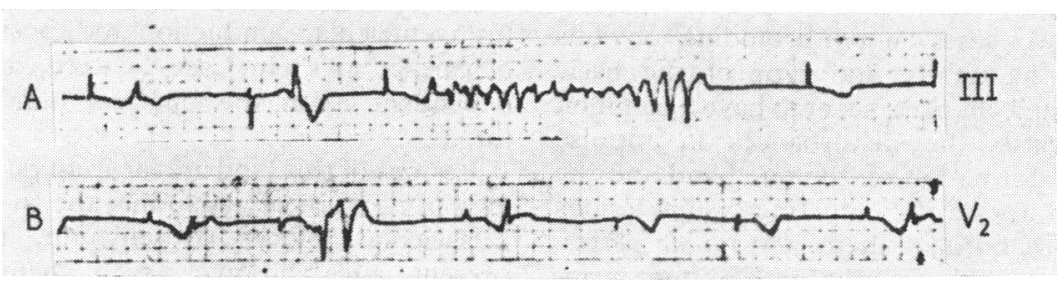

FIG. 4 Electrocardiogram of Case 2. (A) Complete atrioventricular block with ventricular extrasystoles ( $R$ on $T$ type); an extrasystole falls on the terminal $T$ wave of the third $Q R S$ complex, initiating a short run of torsade de pointes. (B) Combined atrio-and intraventricular conduction disturbances, with ventricular extrasystoles. 


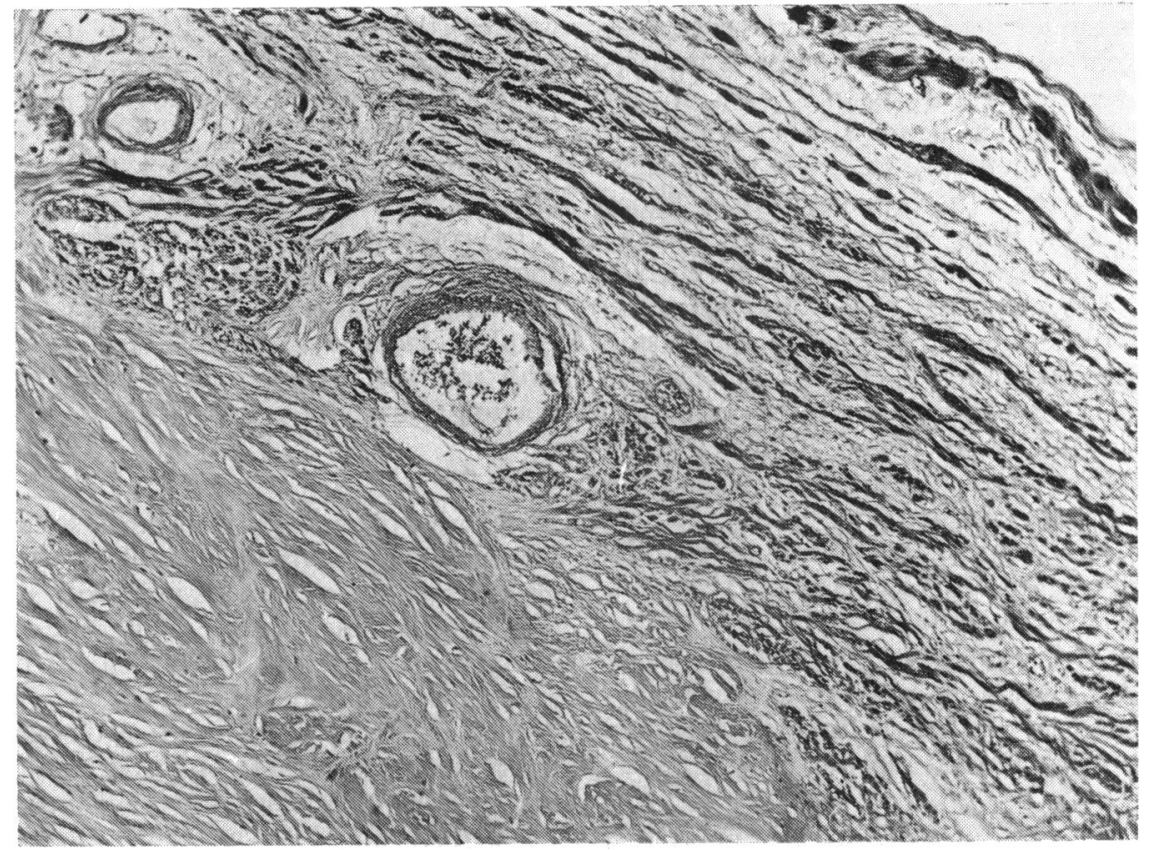

FIG. 5 Case 2. Fibrosis of the atrioventricular node. ( $H$ and $E \times 25$.)

bundle-branch having undergone fine atrophy of the type seen in Lev-Lenègre's disease (Fig. 6). The upper subendocardial part of the right bundle-branch was, also, partially sclerotic (Fig. 6). Patchy myocardial fibrosis and diffuse brown atrophy were seen in the ventricular septum and elsewhere in the heart.

From the clinicopathological standpoint, the presence of a partially fibrotic atrioventricular node and common bundle, with severe but incomplete sclerosis of both bundle-branches, may be correlated with the atrioventricular and bundle-branch conduction disturbances registered in the electrocardiograms.

\section{Discussion}

The present two cases, notwithstanding obvious differences in the nature and type of the basic disease and related changes, seem to have a common pattern as regards the disturbances in impulse conduction and formation on the one hand and the topography and degree of conducting system lesions on the other. In both of them, torsade de pointes occurred against a background of intermittent atrioventricular block of varying degree, associated with transient impairment of bundle-branch conduction and with bursts of ventricular extrasystoles and fibrillation.
The underlying histopathological changes, mostly acute in Case 1 and chronic in Case 2, affected fairly similar tracts of the conducting system, namely the region of the atrioventricular node, the common bundle, and, more particularly, both bundle-branches, without producing a complete disruption of the conducting pathway at any point.

Overall, the disturbances of atrioventricular and intraventricular conduction can be accounted for by the histological findings, but the variable and transient character of the electrocardiographic disorders indicates the likely association of functional factors, which escape precise explanation. The disturbances in atrioventricular impulse transmission should be ascribed mostly to the lesions of the undivided as well as of the branching portions of the conducting system, whereas the impairment in intraventricular conduction and, possibly, the shift of cardiac axis (in Case 1) were, more probably, dependent upon the bilateral bundle-branch injuries.

Lesions of this kind are far from rare in the pathology of heart block, including the so-called tri- and bifascicular blocks (Rosenbaum, 1970). In the present cases, however, such changes interfered, intermittently in a complex way, with impulse conduction and formation, favouring the development of torsade de pointes; clinicopathologically this is an uncommon occurrence. 


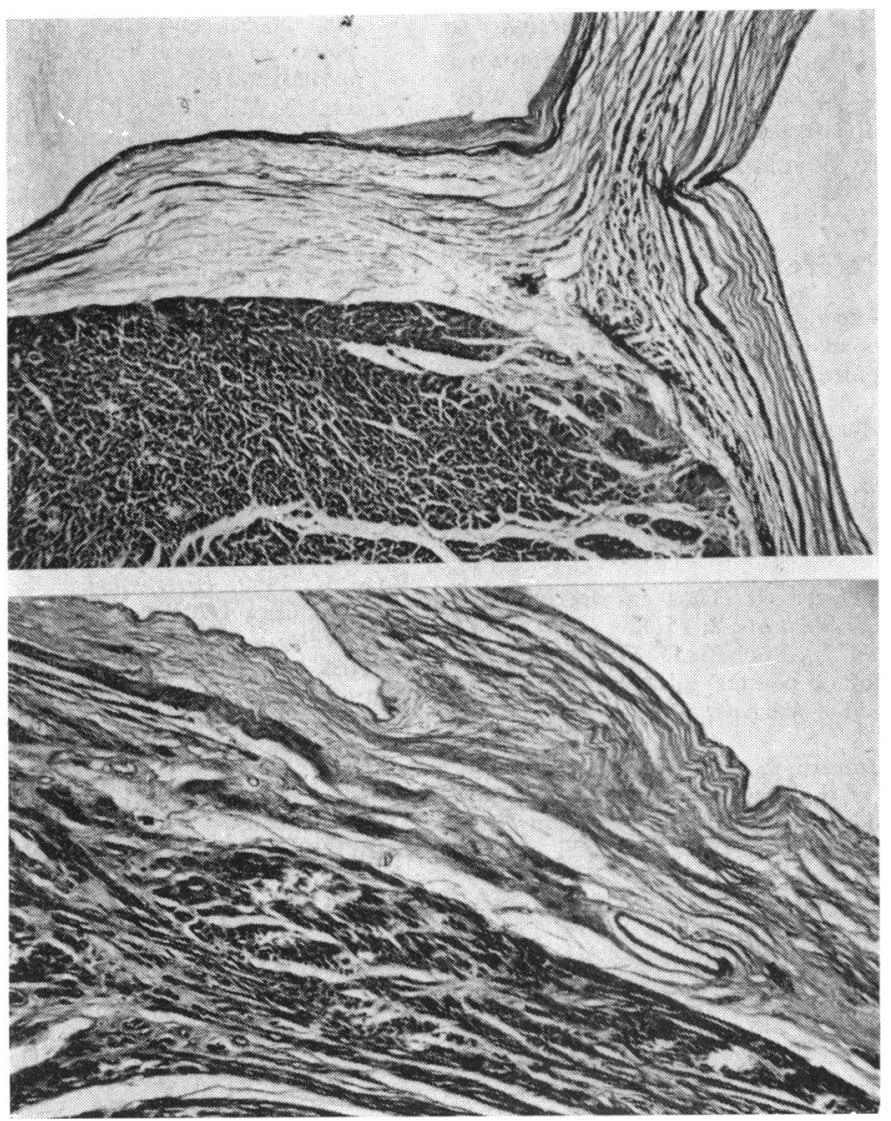

FIG. 6 Case 2. Above: The bifurcation of the His bundle on the right side of the septal summit, with diffuse atrophy of the origin of the left bundle-branch. Below: The partially sclerotic right bundle branch, in its upper subendocardial course. ( $H$ and $E \times 22$.)

Electrophysiological considerations suggest that torsade de pointes occurring in patients with diseased conduction and/or disordered synchronism of the heart beat does not represent chaotic cardiac action from enhanced ectopic (focal) activity, but rather a well-organized electrical process of ventricular reentry (Dessertènne, 1973; Krikler, Curry, and Evans, 1976), the peculiar layout and pattern of which produce cyclic oscillations of $Q R S$ polarity. These pathophysiological considerations suggest, therefore, that a selective histological investigation of the conducting system would be indicated rather than a search for pathological 'foci' somewhere in the heart. Indeed, lesions of the conducting system are not only credited with enhancing cardiac desynchronization in general, but the lesions of the bundle-branches, the left in particular, are held to have a precise bearing on shifts of QRS axis (Watt, Murao, and Pruitt, 1965; Rosenbaum, 1970).

The present histopathological findings are in keeping with this argument and are consistent, to some extent, with current views of the electrophysiology of torsade de pointes, suggesting tentatively anatomofunctional correlation. In these two cases, the multiple lesions of the conducting pathways could have been responsible for conduction blocks with desynchronization, underlying the ventricular tachycardia, while the bilateral incomplete disruptions of the bundle-branches were providing the specific histological basis for the 'coiling' of the QRS axis.

Accordingly, one may postulate that, sometimes, in the presence of heart block and under, so-far, unclear conditions, the affected branches of the conducting system (or the preserved parts of them) may happen to provide the specific re-entry circuit and/or mechanism of torsade de pointes, characterized by periodic twists of the cardiac electrical axis.

Changes of this type, location, and degree, ap- 
parently critical to the pathogenesis of torsade de pointes, are not likely to occur in many patients with heart blocks; which, in turn, could explain why only a few, among all the cases of conduction disturbances, are seen to develop this arrhythmia.

\section{References}

Benaim, R., Calvo, G., Seban, C., Tarrade, Th., and Chiche, P. (1975). Les aspects anatomiques de l'Angor de Prinzmetal: à propos d'une observation anatomoclinique. Archives des Maladies du Coeur et des Vaisseaux, 68, 189.

Dessertènne, F. (1966). La tachycardie ventriculaire à deux foyers opposés variables. Archives des Maladies du Coeur et des Vaisseaux, 59, 263.

Dessertènne, F. (1967). Le complexe electrique ventriculaire à phase lente prolongée. Semaine des Hopitaux de Paris, 43, 539.

Dessertènne, F. (1973). Ordre ou chaos en électrocardiographie. Nouvelle Presse Médicale, 2, 1511.

Evans, T. R., Curry, P. V. L., Fitchett, D. H., and Krikler, D. M. (1976). 'Torsade de pointes' initiated by electrical ventricular stimulation. fournal of Electrocardiology, 9, 255.

Han, J., Millet, D., Chizzonitti, B., and Moe, G. K. (1966). Temporal dispersion of recovery in excitability in atrium and ventricle as a function of heart rate. American Heart fournal, 71, 481.
Krikler, D. M., and Curry, P. V. L. (1976). Torsade de pointes, an atypical ventricular tachycardia. British Heart fournal, 38, 117.

Krikler, D. M., Curry, P. V. L., and Evans, T. R. (1976). Torsade de pointes; an atypical ventricular tachycardia (abstract). British Heart fournal, 38, 311.

MacWilliam, J. A. (1923). Some applications of physiology to medicine. II. Ventricular fibrillation and sudden death. British Medical fournal, $2,215$.

Motte, G., Coumel, Ph., Abitbol, G., Dessertènne, F., and Slama, R. (1970). Le syndrome QT long et syncopes par 'torsades de pointes'. Archives des Maladies du Coeur et des Vaisseaux, 63, 831.

Raynaud, R., Brochier, M., Neel, J. L., Fauchier, J. P., and Raynaud, Ph. (1969). Tachycardie ventriculaire à foyer variable et dyskaliémie. Archives des Maladies du Coeur et des Vaisseaux, 62, 1578.

Rosenbaum, M. B. (1970). The hemiblocks. Diagnostic criteria and clinical significance. Modern Concepts of Cardiozascular Disease, 39, 141.

Rossi, L. (1969). Histopathologic Features of Cardiac Arrhythmias. Casa Editrice Ambrosiana, Milan.

Somerville, W. (1975). Personal communication, quoted by Krikler and Curry (1976).

Watt, T. B., Jr., Murao, S., and Pruitt, R. D. (1965). Left axis deviation induced experimentally in a primate heart. American Heart fournal, 70, 381.

Requests for reprints to Dr. L. Rossi, Via Annunciata 23/4, 20121 Milan, Italy. 